\title{
Investigation of Fragmentation Patterns in Pyridoxal-primary Amine Complexes by Electrospray Ionization Mass Spectrometry
}

\author{
Min-Hee Lee, Bo-Ra Kim, So-Young Kim, and Ho-Tae Kim* \\ Department of Applied Chemistry, Kumoh National Institute of Technology, Kumi 730-701, Korea \\ *E-mail:hotaekim@kumoh.ac.kr \\ Received March 6, 2006
}

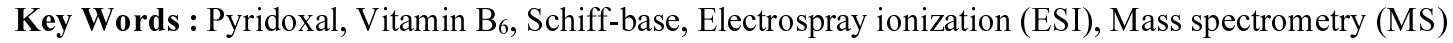

While usually only needed in trace amounts, vitamins are essential nutrients that are required in diet because they cannot be synthesized by an organism itself. Coenzyme vitamin $B_{12}$ is an important cofactor in many biochemical reactions. Aminomutation, the reaction involving the vicinal interchange of an amino $\left(-\mathrm{NH}_{2}\right)$ group and a hydrogen atom, is one of the main vitamin $\mathrm{B}_{12}$-dependent reactions. ${ }^{1-5}$ In the aminomutation reaction, pyridoxal-5'-phosphate (PLP, or vitamin $\mathrm{B}_{6}$ phosphate, which is a biologically active form of vitamin $\mathrm{B}_{6}$ ) is also required for the normal function of vitamin $B_{12} \cdot{ }^{1-3}$ PLP is thought to form a Schiff-base (imine) complex with a reactive amino group in the substrate. The aminomutation reaction is believed to occur upon binding to a substrate site where PLP forms an imine..$^{1-5}$

Earlier studies have focused on the formation, hydrolysis and stability of the Schiff-bases formed by PLP with several amines in aqueous and non-aqueous media. ${ }^{4-9}$ Several computational results regarding the aminomutation reaction are also reported to elucidate the reaction mechanism and to determine the stability and activation energies of the proposed mechanism. ${ }^{2,3,10-13}$ The activation energy barrier for the rate-limiting step in the $\mathrm{B}_{12}$-catalyzed 1,2-amino shift process is estimated to lie between 50 and $75 \mathrm{~kJ} / \mathrm{mol}^{2,3}$

This study focused on the formation and fragmentation pattern analysis of two covalent bond complexes that contained vitamin $\mathrm{B}_{6}$ by mass spectrometry (MS). The investigation of fragmentation patterns in two covalent bond complexes are performed to give some clue to the question, which bond is weak at the intermediate complexes that formed in aminomutation reaction and contained vitamin $\mathrm{B}_{6}$ as a coenzyme.

\section{Experimental Section}

Two covalent bond complexes were formed between the PLP related compound and the three primary amines under the electrospray ionization (ESI) experimental conditions. Pyridoxal (2-methyl-3-hydroxy-4-aldehyde-5-hydroxymethylpyridine $)^{14}$ was used as the PLP related compound. Methylamine, ethylamine, and propylamine were used as primary amines. The experimental MS and MS/MS data for fragmentation pattern analysis were obtained using a Thermo Finnigan LTQ mass spectrometer (Thermo Electron Corp., San Jose, CA, USA) in the gas phase. This mass spectrometer is a linear ion trap mass spectrometer equipped with an atmospheric pressure-ionization source and operated in electrospray ionization mode.

LTQ conditions. All spectra were acquired in positive ion mode over a range of $\mathrm{m} / \mathrm{z} 90-240$ by averaging 30 scans. The heated capillary temperature was set at $100{ }^{\circ} \mathrm{C}$ to facilitate efficient complex formation. The electrospray needle voltage was set at $3.3 \mathrm{kV}$. Nitrogen was used as the sheath gas (flow 20 units) and auxiliary gas (flow 5 units) in the electrospray ionization region. The samples were introduced into the elctrospray interface by a direct infusion method using a microsyringe pump (SEG, Australia) at a flow rate of $10 \mu \mathrm{L} / \mathrm{min}$. The MS/MS spectra were acquired with experimental conditions of an isolation width of 1 mass unit, an activation time of $30 \mathrm{msec}$ and $\mathrm{q}_{\mathrm{z}}=0.25$. In MS/MS mode, the parent ion molecules were manually selected one by one, and each was subjected to collisionally activated dissociation (CAD).

Reagents. Pyridoxal $\cdot \mathrm{HCl}$ (99\%, Sigma-Aldrich Korea), Propylamine (98\%, Sigma-Aldrich Korea), Ethylamine (70 $\mathrm{wt} \%$ solution in water, Sigma-Aldrich Korea), Methylamine (40 wt $\%$ solution in water, Sigma-Aldrich Korea), and $\mathrm{H}_{2} \mathrm{O}$ (HPLC grade, Merck) were used in experiments. Pyridoxal $\mathrm{HCl}$ was dissolved in water to prepare a $2.4 \times 10^{-4} \mathrm{M}$ solution. The three primary amine solutions were prepared in water at a final concentration of $5 \times 10^{-3} \mathrm{M}$. These two solutions were mixed together prior to obtaining the mass spectra.

\section{Results and Discussion}

MS spectra of the three aqueous solutions are shown in Figure 1. A common peak at $\mathrm{m} / \mathrm{z} 168$ observed in (a) pyridoxal + methylamine, (b) pyridoxal + ethylamine and (c) pyridoxal + propylamine solutions which corresponds to the $\left[\text { pyridoxal }+\mathrm{H}^{+}\right]^{+1}$ ion. The three main peaks, labeled (1), (2) and (3) in (a), (b) and (c) solutions correspond to the [Schiff-base complex $\left.+\mathrm{H}^{+}\right]^{+1}$ which are formed between the pyridoxal molecule and the three primary amines. The structures of the three Schiff-base complexes are shown in Scheme 1 as complex 1. Three peaks labeled (4), (5) and (6) in Figure 1 have the mass spectrum pattern [complex $\mathbf{1}+$ $\mathrm{m} / \mathrm{z} 18]$. The proposed complex structures for peaks (4) , (5) and (6) are shown in Scheme 1 as complex 2. 

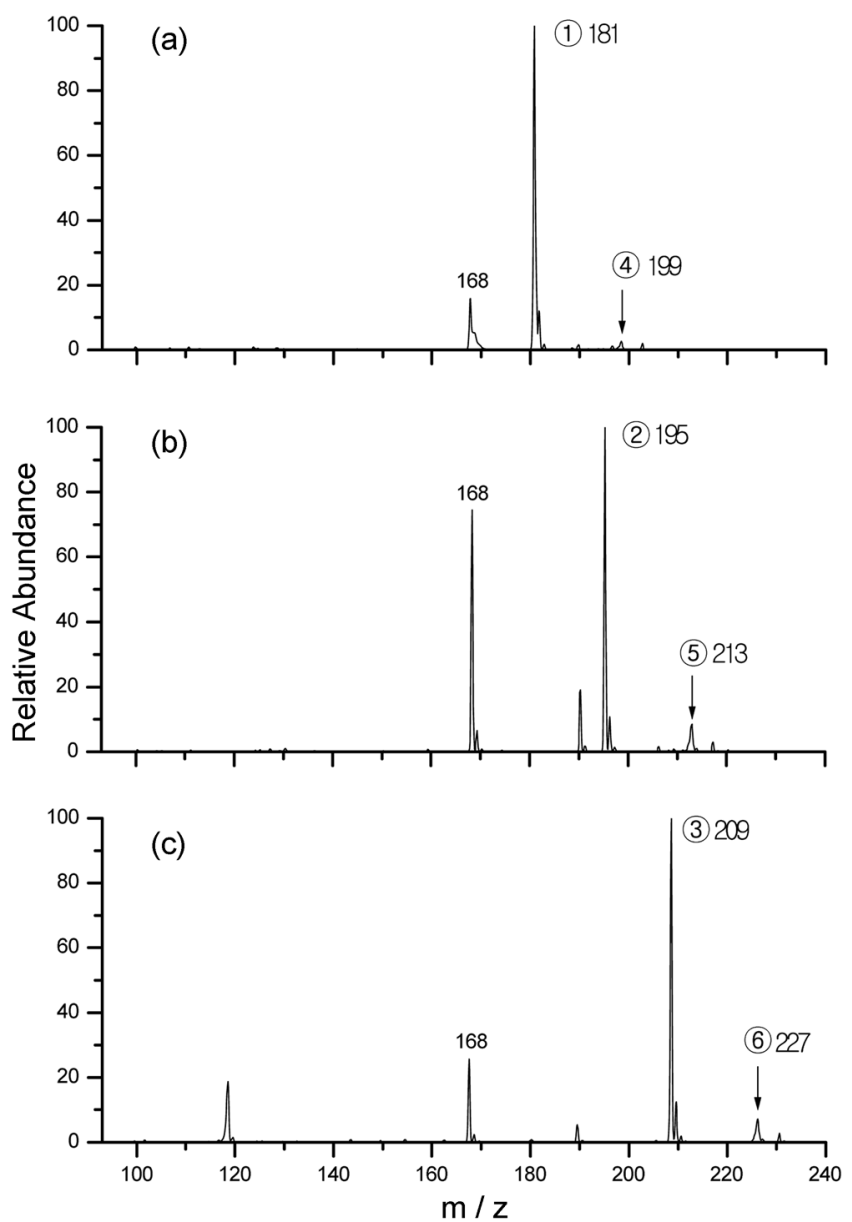

Figure 1. The MS spectra of the aqueous solutions: (a) pyridoxal + methylamine, (b) pyridoxal + ethylamine and (c) pyridoxal + propylamine.

Complex $\mathbf{1}$ is a Schiff-base which is known to have a planar geometry due to the internal hydrogen-bonding structure between the imine nitrogen atom and the hydrogen atom of 3-OH. Complex 2 is supposed to have a non-planar 6-membered ring structure between the nitrogen atom of the primary amine and the oxygen atom of $3-\mathrm{OH}$. It is necessary to note that the 6-membered ring of complex 2 was not a planar structure in the preliminary $a b$ initio calculation results ${ }^{16}$ at the B3LYP level of theory using the Gaussian $98^{17}$ program series. This is because the amine nitrogen atom was not in the plane of the aromatic ring of the pyridoxal molecule. Complex $\mathbf{1}$, a Schiff-base, is generally known as a very stable complex. The stability of complex $\mathbf{1}$ is shown as the intensity ratio in the mass spectrum of Figure 1(b), the pyridoxal + ethylamine reaction system. (The difference in the proton affinities of the two complexes is ignored.) The peak intensity ratio of complex $\mathbf{2}$ to complex $\mathbf{1}$ was about $18 \%$.

MS/MS spectra about complex $\mathbf{1}$ are shown in Figure 2. These MS/MS spectra were taken with $23 \%$ normalized collision energy (NOE) of the complex 1 parent ion in the LTQ mass spectrometer. The common fragment of the three Schiff-bases observed for the form of complex 1 is the peak
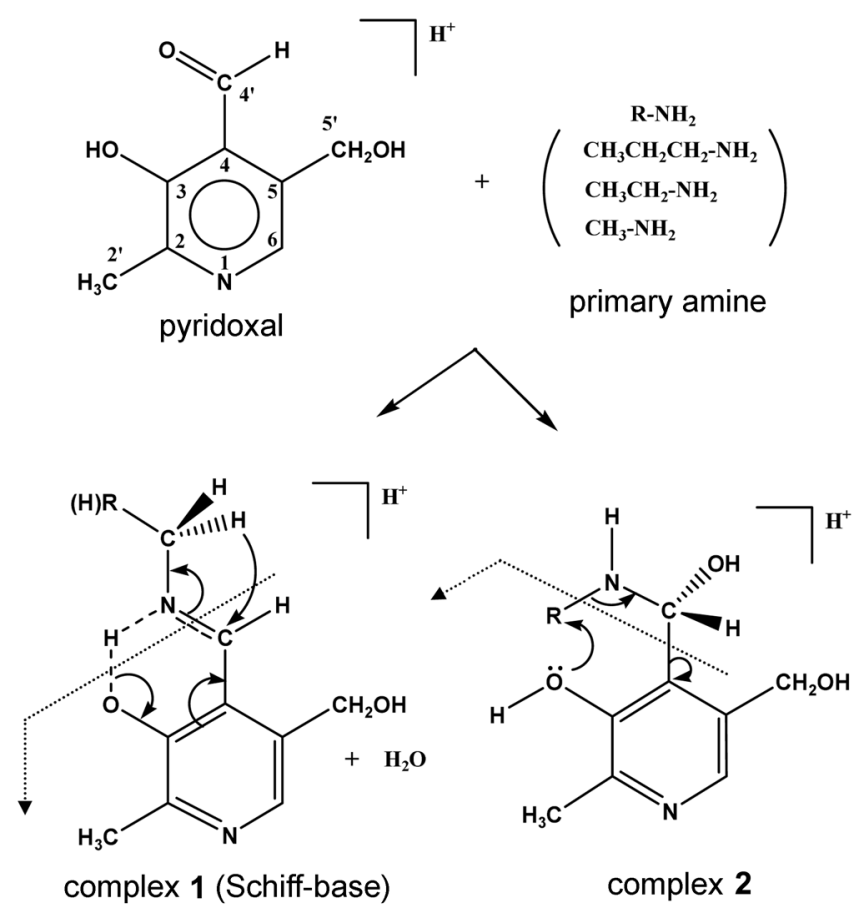

Scheme 1. The structure and reaction mechanism of the two covalent complexes formed between pyridoxal and three primary amines.

at $\mathrm{m} / \mathrm{z} 152$ in Figure 2. The fragment at $\mathrm{m} / \mathrm{z} 152$ is most likely the result of the loss about an alkyl-N(H)- moiety from the three Schiff-bases with the form of complex 1. The alkyl- $\mathrm{N}(\mathrm{H})$ - moiety is divided as a dashed line arrow in complex 1. The one possible dissociation process of complex 1 under collision activation energy is also shown in Scheme 1. It is thought that the $\mathrm{O}-\mathrm{H}$ and $\mathrm{N}=\mathrm{C}$ bonds were weakened because of the internal hydrogen-bonding in complex 1. The common loss of an alkyl-N(H)- moiety from the three Schiff-bases is consistent with the proposed aminomutation mechanism process in which the alkyl- $\mathrm{N}(\mathrm{H})$ moiety of complex $\mathbf{1}$ was regarded as the leaving group in an intermediate complex. ${ }^{2,4,5,15}$

MS/MS spectra of the second covalent complex, proposed as the form of complex 2, are shown in Figure 3. These MS/ MS spectra were taken with $20 \%$ NOE of the complex 2 parent ion in the LTQ mass spectrometer. The fragments at $\mathrm{m} / \mathrm{z} 154$ in (a), at m/z 168 in (b), and at m/z 182 in (c) are thought to be a result of the common loss of a $-\mathrm{NHCH}(\mathrm{OH})$ moiety from the second covalent complexes with the form of complex 2. The - $\mathrm{NHCH}(\mathrm{OH})-$ moiety is divided as a dashed line arrow in complex 2 . It is thought that the bond between the alkyl group and the amine nitrogen atom had been weakened due to the new interaction between the 3-O atom and alkyl group. The $20 \%$ NOE of the complex 2 parent ion in the MS/MS spectra, compared to the $23 \%$ NOE in the MS/MS spectra of complex 1, also shows that the structure of complex $\mathbf{2}$ is less stable than the structure of complex $\mathbf{1}$. The low collisionally activated dissociation energy of complex $\mathbf{2}$ as demonstrated by the MS/MS data also supports the argument regarding the intensity differences of complex 2 

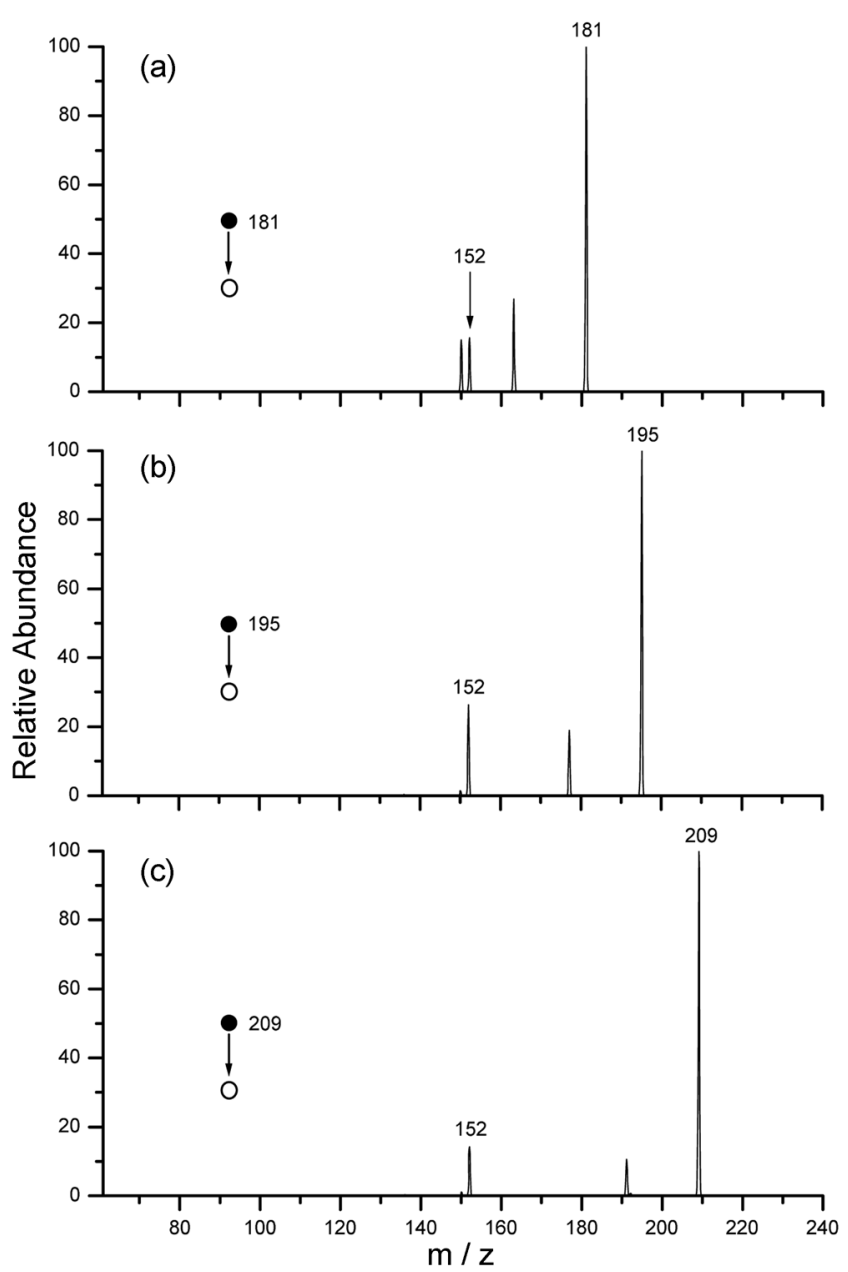

Figure 2. The MS/MS spectra of complex 1 of the aqueous solutions (a) pyridoxal + methylamine, (b) pyridoxal + ethylamine and (c) pyridoxal + propylamine.

compared to complex 1 in the MS spectra of Figure 1.

As a conclusion, an Schiff-base (complex 1) is thought as an important intermediate complex in the aminomutation reaction process because complex 1 fragmentation pattern shows that vitamin $\mathrm{B}_{6}$ coenzyme structure is maintained after the fragmentation process. However, complex $\mathbf{2}$ is not thought as an intermediate complex in the aminomutation reaction because complex 2 fragmentation pattern shows that vitamin $\mathrm{B}_{6}$ coenzyme structure is not maintained after the fragmentation process. In addition, this study does not explain the role of vitamin $\mathrm{B}_{12}$ in the aminomutation reaction process.

Acknowledgements. This paper was supported by Research Fund, Kumoh National Institute of Technology.

\section{References}

1. Garrett, R. H.; Grisham, C. M. In Principles of Biochemistry with a Human Focus; Vondeling, J., Ed.; Thomson Learning, Inc.: U.S.A., 2002; p 459.

2. Wetmore, S. D.; Smith, D. M.; Radom, L. J. Am. Chem. Soc. 2001, 123, 8678 .
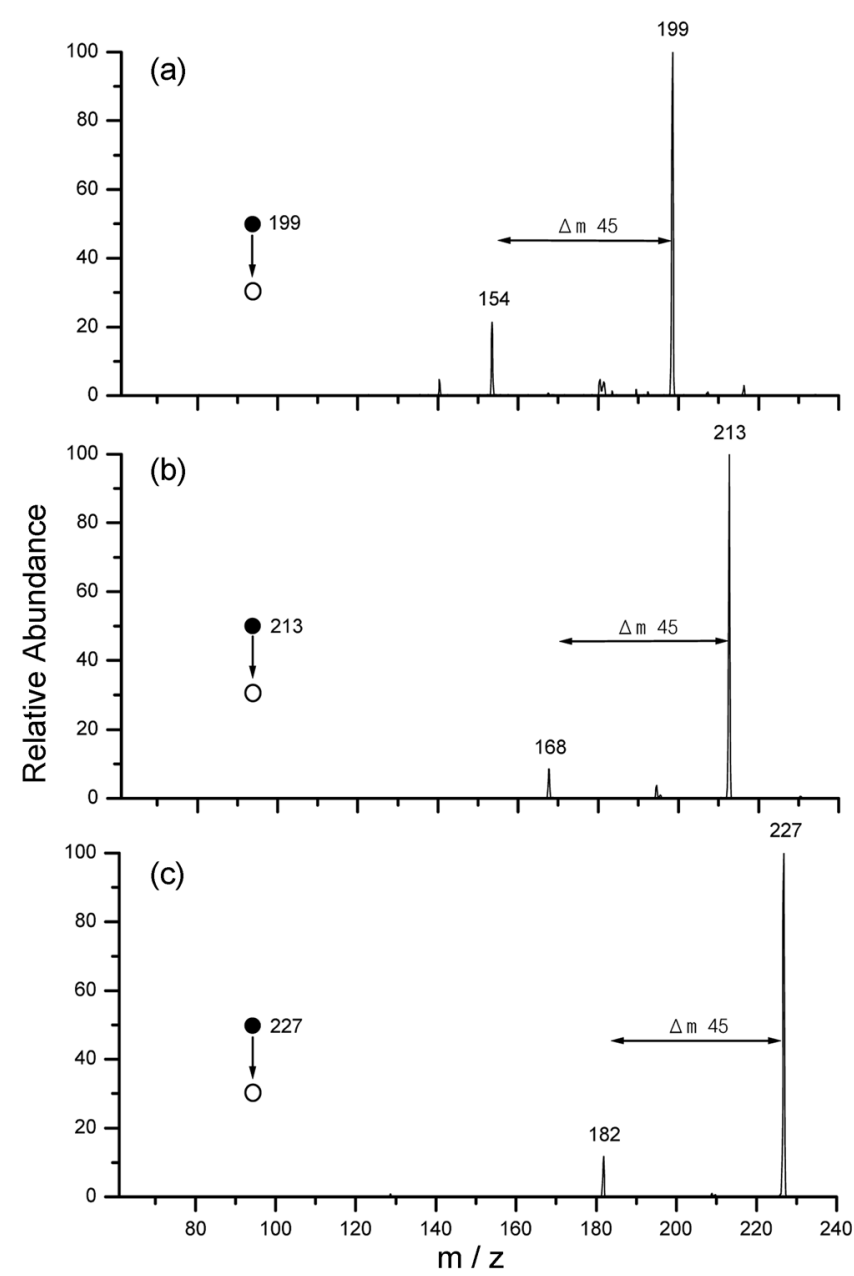

Figure 3. The MS/MS spectra of complex 2 of the aqueous solutions (a) pyridoxal + methylamine, (b) pyridoxal + ethylamine and (c) pyridoxal + propylamine.

3. Wetmore, S. D.; Smith, D. M.; Radom, L. J. Am. Chem. Soc. 2000, 122, 10208 .

4. Hayashi, H.; Mizuguchi, H.; Kagamiyama, H. Biochemistry 1998, 37,15076

5. Toney, D. T.; Kirsch, J. F. Biochemistry 1993, 32, 1471.

6. Vilanova, B.; Adrover, M.; Munoz, F.; Donoso, J. Chemistry and Biodiversity 2004, 1,1073 .

7. Salva, A.; Frau, F.; Munoz, F.; Vilanova, B.; Donoso, J. Biochimica et Biophysica Acta 2003, 1647, 83.

8. Zabinski, R. F.; Toney, D. T. J. Am. Chem. Soc. 2001, 123, 193.

9. Vazquez, M. A.; Donoso, J.; Munoz, F.; Blanco, F. G.; Vado, M. A. G.; Echevarria, G. J. Chem. Soc. Perkin Trans. 2 1991, 1143.

10. Salva, A.; Donoso, J.; Frau, J.; Munoz, F. J. Mol. Struct. (Theochem) 2002, 577, 229.

11. Salva, A.; Donoso, J.; Frau, J.; Munoz, F. Int. J. Quant. Chem. 2002, $89,48$.

12. Smith, D. M.; Golding, B. T.; Radom, L. J. Am. Chem. Soc. 1999, 121,5700

13. Smith, D. M.; Golding, B. T.; Radom, L. J. Am. Chem. Soc. 1999, 121,1383

14. IUPAC-IUB commission on Biochemical Nomenclature, Eur. $J$. Biochem. 1973, 40, 325.

15. Frey, P. A.; Reed, G. H.; Moss, M. L.; Petrovich, R. M.; Ballinger, M. D.; Lieder, K. W.; Wu, W.; Chang, C. H.; Bandarian, V.; Ruzicka, F. J.; LoBrutto, R.; Beinert, H. In Vitamin $B_{12}$ and $B_{12-}$ 
Proteins; Krautler, B., Arigoni, D., Golding, B. T., Eds.; VCH: New York, 1998; pp 435-446.

16. The $a b$ initio calculations are performed in our lab as a preliminary calculation.

17. Frisch, M. J.; Tucks, G. W.; Schlegel, H. B.; Scuseria, G. E.; Robb, M. A.; Cheeseman, J. R.; Zakrzewski, V. G.; Montgometry, J. A.; Stratmann, R. E.; Burant, J. C.; Dapprich, S.; Millam, J. M.; Daniels, A. D.; Kudin, K. N.; Strain, M. C.; Farkas, O.; Tomasi, J.; Barone, V.; Cossi, M.; Cammi, R.; Mennucci, B.; Pomelli, C.;
Adamo, C.; Clifford, S.; Ochterski, J.; Peterson, G. A.; Ayala, P. Y.; Cui, Q.; Morokuma, K.; Malick, D. K.; Rabuck, A. D.; Raghavachari, K.; Foresman, J. B.; Cioslowski, J.; Ortiz, J. V.; Stefanov, B. B.; Liu, G.; Liashenko, A.; Piskorz, P.; Komaromi, I.; Gomperts, R.; Martin, R. L.; Fox, D. J.; Keith, T.; Al-Laham, M. A.; Peng, C. Y.; Nanayakkara, A.; Gonzalez, C.; Challacombe, M.; Gill, P. M. W.; Johnson, B. G.; Chen, W.; Wong, M. W. Andres, J. L.; Head-Gordon, M.; Replogle, E. S.; Pople, J. A. Gaussian 98; Gaussian, Inc.: Pittsburgh, PA, 1998. 